\title{
The political economy of migration enforcement: domestic versus border control*
}

\author{
Giovanni Facchini† and Cecilia Testa
}

August 25, 2014

\begin{abstract}
We study migration policy enforcement by an elected government. The policy-maker faces uncertainty on the supply of migrants, but has more information than the public on its preferences and the extent and effectiveness of its enforcement activities. We show that a utilitarian government preferring more migrants than the majority may find it optimal to set a restrictive target to please the median voter, while relaxing its enforcement to admit more foreigners in a concealed way. Lax enforcement may be achieved either by deploying inadequate resources on cost-effective activities (domestic enforcement) or by allocating a larger budget on less effective tools (border enforcement). The attractiveness of one instrument over the other depends on the size of the immigrant flow: if the supply is large, border enforcement might be preferred because, although more costly, it brings the number of migrants closer to the utilitarian optimum. Hence, re-election concerns might provide a rationale for the widespread use of less a effective enforcement tool, such as border control.
\end{abstract}

JEL classification: F22, J61.

Keywords: Illegal immigration, Immigration Policy, Political Economy.

\footnotetext{
*We would like to thank participant to the CES Ifo Economic Studies Conference on Migration for useful comments.

${ }^{\dagger}$ University of Nottingham,CEPR, CES-Ifo, CReAM, GEP, IZA and LdA; giovanni.facchini@nottingham.ac.uk.

${ }^{\ddagger}$ Royal Holloway University of London and LdA; email: cecilia.testa@rhul.ac.uk.
} 


\section{Introduction}

Illegal immigration is widespread because, although tight migration quotas tend to be the norm, governments in practice fail to enforce them. One simple explanation is that destination countries are unable to implement policies because of the limited tools at their disposal. At the same time, Hanson and Spilimbergo (2001) and Fasani (2009) - amongst others - have argued that the pressure applied by those sectors that intensively use illegal immigrants might be responsible for the lax policy enforcement. In other words, the observed large number of illegal immigrants might be the result of both a lack of instruments, and an intentional government policy, which responds to the needs of specific economic interests. ${ }^{1}$

In particular, underfunding of enforcement agencies has been a chronic issue in the United States, the United Kingdom and other countries. ${ }^{2}$ Moreover, the limited resources available are often allocated to policy tools, like border enforcement, that are not particularly effective in achieving the objective of reducing illegal immigration, rather than to more effective instruments like worksite inspections. In fact, as pointed out by United States General Accounting Office (2005), "worksite enforcement was a low priority for the Immigration and Naturalization Service (INS) and continues to be a low priority for Immigration and Custom Enforcement (ICE)..." Table 1 corroborates this view. Between 1999 and 2003, the average number of officers' hours devoted to line-watch border patrol was thirty times as large as the number of officers' hours devoted to worksite inspections. At the same time, border apprehensions were only ten times larger than interior apprehensions, suggesting that in terms of officers' hours, each border apprehension is three times more costly than an interior one.

The migration policy enforcement priorities pursued by U.S. agencies have led several observers to conclude that the ineffective use of resources is driven by political constraints (Cornelius et al. 2004, Hanson 2006, Massey et al. 2002) and importantly, the experience of the United States is shared by many other countries. For example, Italy has recently implemented tighter border controls, even if this is unlikely to have the desired effects. ${ }^{3}$

What drives the slack in migration policy enforcement? Which factors explain the use of ineffective enforcement tools, such as border control? We answer these questions proposing a

\footnotetext{
${ }^{1}$ For an analysis of the role of lobbies in shaping official immigration policy in the United States, see Facchini, Mayda, and Mishra (2011).

${ }^{2}$ Even the recent immigration reform proposal, i.e. the "Border Security, Economic Opportunity, and Immigration Modernization Act", (S.744, 2013), contained a provision to increase by 40 billions the budget devolved to border enforcement over the next decade, including adding 20000 Border Patrol agents and 700 miles of fencing along the Southern border (New York Times, "Senate, 68 to 32 Passes Overhaul for Immigration", June 27, 2013). This clearly suggests that underfunding continues to be perceived as a serious issue in the United States. In the UK, a recent report by the House of Commons Home Affairs Committee has pointed out that the resources available to the enforcement agency are also grossly inadequate. See House of Commons, Home Affairs Committee (2011).

${ }^{3}$ As argued by Triandafyllidou (2009) "Although Italy is sadly famous for the images of clandestine immigrants landing on the shores of its Southern coasts, official records show that migrants arrived via boats represent only a small fraction (4\%-16\% in the period 2000-2006) of the existing stock of undocumented residents."
} 
reputation building model based on Facchini and Testa (2014), where voters and the policy maker may have divergent preferences over immigration, and the latter can use different tools to control migration flows, namely domestic and border enforcement. The migration policy is the outcome of a simple two-period political agency model. During each term in office an incumbent politician sets a migration policy that involves an official migration target, determining the number of migrants to be admitted legally, and the extent of enforcement to be carried out either domestically or at the border. The latter is assumed to be less effective, as it requires the expense of more resources to achieve the same migration target. When enforcement fails to deliver the chosen migration target, illegal immigration emerges. As in Facchini and Testa (2014), voters are heterogeneous in their factor endowments, and richer individuals prefer more foreign workers. Thus, under standard income distributions (Alesina and Rodrik 1994, Dutt and Mitra 2002), the median prefers less migrants than the average voter. As typical in political agency models, we assume uncertainty on the state of the world - in our case the supply of migrants that can be either large or small - and asymmetric information about the politician's preferences. Namely, the public does not know whether the incumbent is populist (i.e. his preferences are perfectly aligned with those of the median voter), or utilitarian (i.e. he shares the preferences of the average citizen). ${ }^{4}$

In this environment, voters use outcome measures of performance - i.e. the total number of migrants in the country - to gauge the incumbent's type. Since incumbents desire reelection, because of the influence they wield in determining policy, then electoral incentives will affect policy choices. When only one enforcement tool is available, Facchini and Testa (2014) show that a simple "reputation-building" equilibrium can arise where a utilitarian incumbent overrides his personal preferences to gain the support of the median voter. To that end, he sets a migration target that responds to the median voter's interests, but underinvests in its enforcement to de facto admit more foreign workers as illegals.

How do multiple tools affect the incentives faced by the government? In particular, why should the incumbent choose to invest in border control, even if the other tool is more cost effective? To answer this question we allow the incumbent government to strategically choose not only the budget allocated to enforcement activities, but also how resources are channeled toward each tool. Analyzing the choice between the two enforcement technologies, we show under what condition a reputation building equilibrium can emerge, where the incumbent finds it is desirable to set a target pleasing the median voter, while relaxing its enforcement by using a less cost-effective instrument like border enforcement. Our results indicate that the size of the supply of migrants, which is not observed either by the politician or the public, is key to determine the desirability of one instrument over the other. In particular, if the supply of foreign workers is small, domestic enforcement is favored because it delivers the same migration target while employing less resources.

\footnotetext{
${ }^{4}$ The presence of a utilitarian politician in the model captures the public opinion gap in immigration policy that has been identified by Chiswick and Hatton (2003).
} 
On the other hand, if the supply is large, border enforcement might be preferred because, although more costly, it might bring the number of migrants closer to the utilitarian optimum, thus reducing the policy distortion driven by strategic motives. As a result, if the expected gain in the large supply scenario is big enough, border enforcement will be chosen. The analysis of two enforcement technologies also delivers another important result: when the government can choose not only the enforcement budget but also how to use it, illegal immigration driven by strategic motives arises more often because, by channeling resources toward border enforcement, the incumbent is able to sustain a reputation building equilibrium that could not occur with one instrument alone. Consequently, even if border enforcement may reduce the policy distortion induced by strategic behavior, its very availability implies that strategic lax enforcement can be more easily carried out.

Our analysis builds on the literature that has investigated the political economy forces that shape immigration policy making (e.g. Benhabib 1996, Ortega 2005, Facchini and Willmann 2005 and Facchini and Testa 2014). It is also related to the body of works that have considered the effectiveness of different migration policy instruments from the point of view of the maximization of the destination country's aggregate welfare (e.g. Ethier 1986, Bond and Chen 1987 and Chau 2001). In particular, it provides a positive analysis that can rationalize why elected politicians choose what many scholars have identified as an ineffective instrument to limit the inflow of undocumented foreigners. The remainder of the paper is organized as follows. Section 2 introduces the framework used in the analysis, while section 3 studies the political desirability of border and domestic enforcement. Section 4 concludes.

\section{A model of illegal immigration}

To study the migration policy formation process we lay out a reputation building model based on Facchini and Testa (2014), where the preferences of voters and policy-maker over the optimal number of migrants may diverge, opening the possibility that the incumbent distorts his policy choices to gain re-election. In particular, we consider a small open economy (Home) producing a single good using labor $E$ according to a production function $Y=F(E)$, with $F^{\prime}(E)>0$, $F^{\prime \prime}(E)<0 . F(E)$ is such that there exists a well-defined profit function associated to it, and the corresponding monetary payment can be interpreted as the compensation received by an immobile factor. ${ }^{5}$ As for prices, let aggregate output be the numéraire, the real wage in Home be denoted by $w$, and the profit function be given by $\pi(w)$.

The economy is populated by a continuum of native individuals indexed by $i \in[0,1]$, whose mass is normalized to one. Every individual $i$ supplies one unit of labor, and receives a fraction

\footnotetext{
${ }^{5} \mathrm{~A}$ natural candidate would be land, or alternatively capital.
} 
$\lambda_{i}>0$ of the profits, with $\int \lambda_{i} d i=1 .{ }^{6}$ Furthermore, we assume the domestic wage under autarky to be larger than the wage prevailing in the rest of the world. Thus, abstracting from moving costs, foreign workers will always find it desirable to relocate to Home. To capture the uncertainty in immigration pressure, the supply $\hat{I}$ of migrants is assumed to be stochastic, and depending on the state of the world $s$, which can be either high $(H)$ or low $(L)$ with probabilities $q$ and $1-q$ respectively. In particular, let $\hat{I}(L)=\underline{I}<\bar{I}=\hat{I}(H)$.

Admitting immigrants $I$ leads to welfare gains for Home, which are bounded by the presence of a "congestion" cost $c(I)$, which is a differentiable, increasing and convex function. Limiting the migrant's inflow involves a policy enforcement cost $\eta[\hat{I}(s), I]$ that depends on the supply of foreign workers $\hat{I}(s)$ and the target $I$ chosen by the government.

The utility of a native individual $i$, for a given state of the world $s$, can therefore be written as

$$
u_{i}[I, \widehat{I}(s)]=\lambda_{i} \pi[w(1+I)]+w(1+I)-c(I)-\eta[\widehat{I}(s), I]
$$

where $1+I$ represents total employment of natives and migrants in the country. ${ }^{7}$ The first term on the right hand side captures the individual's share of profits, the second his wage income, whereas the third and fourth terms denote the congestion and the policy enforcement costs, that are equally shared among all citizens. Assuming that the enforcement cost is a linear decreasing function of the migration target and that for any target a larger supply $\hat{I}$ of migrants has a positive effect on both the total and the marginal cost of enforcement (i.e. $\eta(I, \bar{I})>\eta(I, \underline{I})$, and $\left|\frac{\partial \eta}{\partial I}(I, \underline{I})\right|>\left|\frac{\partial \eta}{\partial I}(I, \bar{I})\right|$ for all $\left.I\right),{ }^{8}$ Lemma 1 in Facchini and Testa (2014) shows that, as long as the congestion cost is sufficiently convex, the number of migrants maximizing individual utility under the state of the world $s$ is an increasing function of $\lambda_{i}$. Moreover, for a given $\lambda_{i}$ the optimal number of migrants preferred by individual $i$ in the high state of the world $\left(I_{i}^{*}(H)\right)$ is larger than the number preferred in the low state of the world $\left(I_{i}^{*}(L)\right)$.

Knowing the probability of each state of the world, $i$ 's expected utility can be written as

$$
E\left[u_{i}(I)\right]=q u_{i}(I, \bar{I})+(1-q) u_{i}(I, \underline{I})
$$

Given that $u_{i}(I)$ is linear in its stochastic component, ${ }^{9}$ the migration target $I_{i}^{*}$ maximizing

\footnotetext{
${ }^{6}$ We assume the distribution of factor ownership to be atomless i.e., that every agent only owns a tiny fraction of the total supply of the fixed factor. Notice that if we denote with $K_{i}$ agent's i supply of the fixed factor, $\int_{I} K_{i} d i=K$. Since population size is normalized to $1, K$ is also the average supply of the fixed factor in the population. Define $\lambda_{i}=\frac{K_{i}}{K}>0$. Then $E\left(\lambda_{i}\right)=\int_{I} \lambda_{i} d i=1$. In other words, $\lambda_{i}$ can be interpreted as the holding of the fixed factor by agent $i$ relative to the population average.

${ }^{7}$ In other words, native and immigrant labor are perfect substitutes in production. This assumption simplifies the analysis of model, and allowing for imperfect substitutability, while complicating the algebra, would not significantly affect our conclusions.

${ }^{8}$ An example of such an enforcement cost function is given by $\eta_{s}=a_{s}[\hat{I}(s)-I]$, where $s \in\{L, H\}$, with $a_{H}>a_{L}$.

${ }^{9}$ This implies that the policy maker is risk neutral.
} 


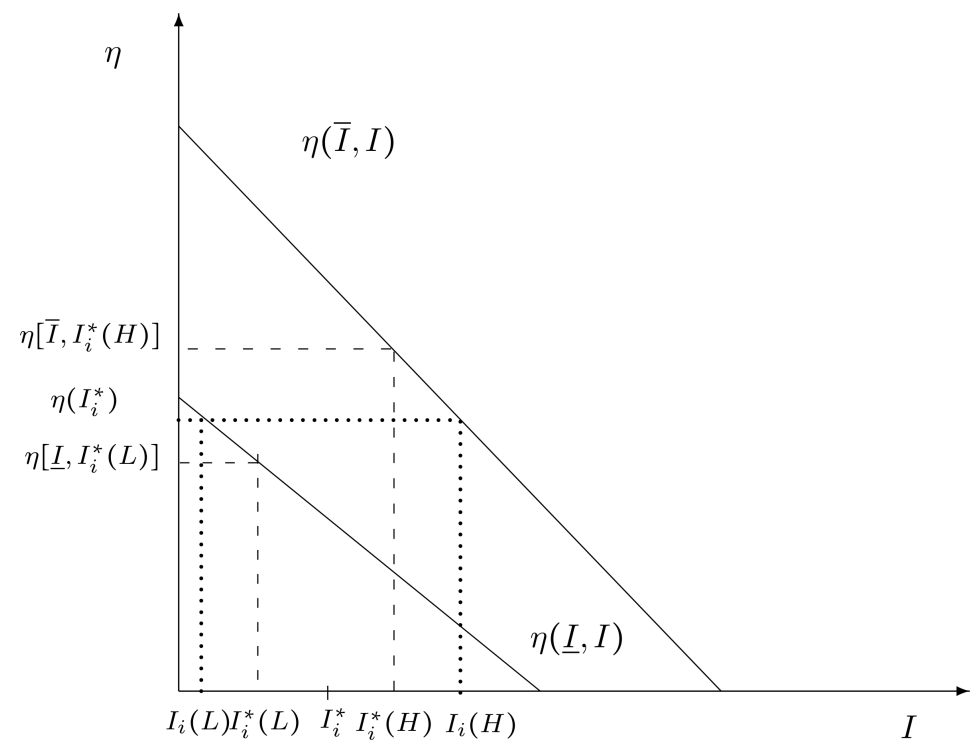

Figure 1: Illegal immigration

expected utility is given by:

$$
I_{i}^{*}=(1-q) I_{i}^{*}(L)+q I_{i}^{*}(H)
$$

where $I_{i}^{*}(H)$ and $I_{i}^{*}(L)$ are respectively the optimal number of migrants under the high and low state of the world. Moreover, since $\eta$ is linear in $I$, the corresponding expected policy enforcement cost is given by:

$$
\eta\left(I_{i}^{*}\right) \in\left(\eta\left[\underline{I}, I_{i}^{*}(L)\right], \eta\left[\bar{I}, I_{i}^{*}(H)\right]\right)
$$

Note that since the enforcement budget is chosen under imperfect information on the state of the world, the migration target cannot be exactly met. In particular, ex-post, given the realized supply of foreign workers, the actual number of migrants, denoted by $I_{i}(s)$, differs from the state contingent optimal target $I_{i}^{*}(s)$. This point is intuitively explained using figure 1 , where we represent the enforcement cost functions under the two possible states of the world. If the state of the world is high, to obtain the optimal immigration level $I_{i}^{*}(H)$, individual $i$ should spend $\eta\left[\bar{I}, I_{i}^{*}(H)\right]$. Hence, having spent only

$$
\eta\left(I_{i}^{*}\right)<\eta\left[\bar{I}, I_{i}^{*}(H)\right]
$$

the actual number of migrants is $I_{i}(H)>I_{i}^{*}$. At the same time, given the information constraint, $I_{i}^{*}$ maximizes his expected utility. The difference $I_{i}(H)-I_{i}^{*}$ represents the number of illegal immigrants. On the other hand, if the state of the world is low, the individual over-invests in enforcement, and the number $I_{i}(L)$ of immigrants actually entering the country is lower than the target, $I_{i}^{*}$. Moreover, Facchini and Testa (2014) show that illegal immigration is larger, the more 
restrictive is the migration target $I_{i}^{*}$. If the migration policy is chosen by majority voting, then it will reflect the preferences of the median voter, and will in general differ from those of the average voter (which coincide in this set-up with aggregate welfare). In particular, since under typical wealth distributions the median is poorer than the average (Alesina and Rodrik 1994), the median voter will prefer a smaller number of migrants than the average voter. As a result, illegal immigration is higher if the policy preferred by the median instead of the average voter is chosen.

Within this economic environment, Facchini and Testa (2014) study how the divergence of preferences between the incumbent government and the median voter can distort migration policy. To this end, they consider a model of elections with two periods, and where in each period the politician in office chooses a migration policy. Between periods there is an election in which voters decide whether to re-elect or not the incumbent, and the median voter plays a decisive role. Politicians may be one of two types $g \in\{p, b\}$. The first type is a "populist" $(p)$ and has preferences perfectly aligned with the median voter; the second type is "utilitarian" (or Bethamite, $b$ ), and has preferences aligned with the average voter. A politician $g$ maximizes his expected intertemporal utility given by $U_{g}(I)=E\left[u_{g, 1}(I, \hat{I}(s))\right]+\sigma u_{g, 2}$ where $u_{g, t}, t=1,2$ are the per period payoffs defined in equation $1, \sigma$ is the probability of re-election, and the future is not discounted.

The types of the first period incumbent and challenger are draws from an identical distribution, and the probabilities that the politician is populist or utilitarian are denoted by $\mu$ and $1-\mu$ respectively. The type of the politician is only known to himself, whereas the distribution of types is common knowledge. In the first period, the supply of foreign workers $\widehat{I}(s)$ is not observed either by the politician or the public, but they both know its distribution. Thus, in the first period the incumbent chooses a migration policy prescribing a target and the amount of resources to be spent on enforcement, under imperfect information on the actual supply of foreign workers. Voters, having observed the target and the actual number of migrants, but neither their true supply nor the amount of resources spent on enforcement, revise their beliefs on the incumbent's type according to Bayes rule, and choose whether to re-elect or replace him with a challenger. In the second period, the state of the world is revealed, the elected politician chooses again the number of immigrants to be admitted and the world ends. Uncertainty on potential migration flows, and the government's superior information over important aspects of policy design, make it difficult for the voter to punish or reward the incumbent. We consider two possible sources of information asymmetry. First, the public might not be informed on the budgetary aspects of migration policy, and this may allow the politician to exploit his information advantage to strategically under-invest. Second, voters may not be aware of the characteristics of the enforcement technologies available to the policymaker, and thus they can fall victim of a strategic misallocation of the resources towards a less effective policy instrument. Of course, in the real world the public might be able to obtain some information on the budget or the enforcement technology adopted, but this information is 
unlikely to be perfect. ${ }^{10}$ To capture this idea and to keep our analysis tractable, we thus assume that enforcement is not observable.

\section{$2.1 \quad$ Equilibrium}

The above structure defines a game of incomplete information between voters and politicians that can be solved by backward induction. In this section we characterize the equilibrium policy choice assuming that only one tool (domestic enforcement) is available, and we will subsequently generalize our analysis allowing the policy-maker to choose between border and domestic enforcement. A perfect Bayesian equilibrium of the above described game consists of a migration policy, a voting rule and set of beliefs such that $(a)$ voters' beliefs are generated by Bayesian updating, $(b)$ the voting rule is optimal given the voters' beliefs and the politicians' strategies and $(c)$ the incumbent's strategy is optimal given the voters' beliefs and the opponent's and voters' strategies.

In the second period, because there are no further elections, the incumbent chooses the policy maximizing his own utility, and since he can observe the supply of foreign workers, he chooses the optimal amount of enforcement (i.e. there is no illegal immigration). In the first period, the policy choice is more complex because of re-election concerns, and it crucially depends on voters' beliefs. Let $P\left[g=p \mid I_{g}, I(s)\right]$ be the ex-post probability that the incumbent $(g)$ is a populist $(p)$ when the observed number of migrants is $I(s)$ and the target is $I_{g}$. Focussing on monotonic beliefs, ${ }^{11}$ a populist incumbent will always choose the policy preferred by the median voter because, by doing otherwise, he cannot strengthen his reputation of being a populist, and hence increase his chances of re-election. The same logic does not apply to the utilitarian type though. In the first period, if he chooses the migration policy preferred by the average voter (sincere strategy), he can only decrease his ex-post probability of being considered a populist, whereas by "pooling" with a populist, he may raise it. Given the assumption of monotonic beliefs, in order to "pool",

\footnotetext{
${ }^{10}$ In fact, even researchers have hardly been able to collect detailed systematic data on spending on enforcement. To understand the nature of the problem, consider for example the case of the United States. In this context two agencies are responsible for the enforcement of migration policy (U.S. Customs and Border Protection and U.S. Immigration and Customs Enforcement (ICE)), but they also carry out a series of other duties - ranging from the prevention of smuggling of contraband, to the prosecution and deportation of non-citizens who have been convicted of a felony in the US etc. The publicly available data refer only to aggregate budgets, which make it impossible to precisely measure the resources allocated to each particular activity especially given that these agencies have substantial flexibility in the allocation of their resources. In particular United States General Accounting Office (2005) points out that “... After September 11, 2001, INS and ICE focused their resources on national security-related investigations. According to ICE, the redirection of resources from other enforcement programs to perform national security-related investigations resulted in fewer resources for traditional program areas, like worksite enforcement and fraud."

${ }^{11}$ Monotonic beliefs imply that whenever the median voter observes a migration target and a number of migrants coinciding with his most preferred one, he does not revise downward the probability that the incumbent has his same preferences, and viceversa. This assumption, as in Coate and Morris (1995), insures that the politician with preferences aligned with the voter will not have incentives to distort his policy. An alternative assumption leading to the same equilibrium outcome would be that the populist does not behave strategically. See Besley and Smart (2007).
} 
the utilitarian politician must (i) set the median voter's most preferred target $I_{p}^{*}$; and (ii) choose a level of enforcement that allows him to replicate the same number of migrants admitted by a populist at least under some state of the world. This is possible using three strategies. First, the amount spent on enforcement coincides with $\eta\left(I_{p}^{*}\right)$, so that the number of migrants admitted always equals the one chosen by a populist. We label this strategy "mimicking". Second, the enforcement expenditure could be set at a level $\eta_{u}<\eta\left(I_{p}^{*}\right)$ such that, if the state of the world is low, the migration level $I_{b}^{u}(L)$ equals that generated by a populist type under the high state of the world, i.e. $I_{b}^{u}(L)=I_{p}(H)$. On the other hand, if the state of the world is high, the number of foreign workers entering the country will be higher than the upper-bound obtained by the populist, i.e. $I_{b}^{u}(H)>I_{p}(H)$. We label this strategy "under-investment". Third, enforcement could be set at a level $\eta_{o}>\eta\left(I_{p}^{*}\right)$ allowing to "pool" with the populist only if the state of the world is high, whereas if it is low, the number of migrants will be smaller than the lower-bound obtained by the populist i.e. $I_{b}^{o}(L)<I_{p}(L)$. Note that in the last scenario illegal immigration will never arise, and for this reason we focus on the first two strategies, i.e. those relevant for the analysis of illegal immigration.

As argued by Facchini and Testa (2014), the process of updating voters' beliefs can be described as follows. Since a populist politician always chooses the migration target and the enforcement level preferred by the median voter, whenever the median voter observes a target different from $I_{p}^{*}$ or a level of migration different from either $I_{p}(H)$ or $I_{p}(L)$, he concludes that the incumbent is utilitarian. On the other hand, denoting by $\gamma_{s}$ the probability that a utilitarian incumbent admits a total number $I_{p}(H)$ of migrants when the state of the world is $s \in\{H, L\}$, then if voters observe the target $I_{p}^{*}$ and the outcome $I_{p}(H)$, the ex-post probability that the incumbent is a populist can be computed as follows:

$$
P\left[g=p \mid I_{p}^{*}, I_{p}(H)\right]=\frac{\mu q}{\mu q+q(1-\mu) \gamma_{H}+(1-q)(1-\mu) \gamma_{L}}
$$

where $\mu q$ is the probability that $I_{p}(H)$ is generated by a populist, $q(1-\mu) \gamma_{H}$ is the probability that it is generated by a utilitarian type mimicking the populist, and $(1-q)(1-\mu) \gamma_{L}$ is the probability that it is generated by a utilitarian type under-investing in enforcement. In the remainder of our analysis, to save on notation, we will drop the target $I_{p}^{*}$ from the definition of the conditional probabilities, as it is the same under all strategies we consider.

If mimicking is chosen, then $\gamma_{H}=1$ and $\gamma_{L}=0$, which implies that $P\left[g=p \mid I_{p}(H)\right]=\mu$, i.e. the ex-ante and ex-post probabilities of the incumbent being populist are the same. On the other hand, if under-investment is chosen, then $\gamma_{H}=0$ and $\gamma_{L}=1$, and:

$$
P\left[g=p \mid I_{p}(H)\right]=\frac{\mu q}{\mu q+(1-q)(1-\mu)}
$$


Note that $\frac{\mu q}{\mu q+(1-q)(1-\mu)}>\mu$ if and only if $q>\frac{1}{2}$. In other words, under-investment can generate an upward revision of the ex-ante probability that the incumbent is a populist only if "pooling" is sufficiently costly for the utilitarian incumbent (i.e. $q$ is sufficiently large). This is because the larger is $q$, the higher is the probability that by under-investing he will end up revealing his type.

Given this structure of beliefs, a sequentially rational voting rule for the median voter is to retain the incumbent if and only if he believes that the ex-post probability that the incumbent is a populist is strictly larger than the ex-ante probability, i.e. $P[g=p \mid I(s)]>\mu .{ }^{12}$ Based on the voting strategy described above, mimicking is never optimal because in this case $P\left[g=p \mid I_{p}(H)\right]=\mu$. For the same reason, if $q \leq 1 / 2$, under-investment cannot be optimal. On the other hand, if $q>\frac{1}{2}$, under-investment might be optimal because if the state of the world turns out to be low, the incumbent is re-elected, and in the second period he will be able to choose his most preferred number of migrants $I_{b}^{*}(L)$.If the state of the world is instead high, he will be replaced by a challenger who is populist with probability $\mu$ and utilitarian with probability $1-\mu$. We are now ready to write the expected payoff of the utilitarian politician and to simplify notation we will drop the index $i=b$. If the under-investment strategy is chosen, the payoff is given by:

$$
U(\text { under })=(1-q) u\left[I_{p}(H)\right]+q u\left[I_{b}^{u}(H)\right]+(1-q) u\left[I_{b}^{*}(L)\right]+q\left\{\mu u\left[I_{p}^{*}(H)\right]+(1-\mu) u\left[I_{b}^{*}(H)\right]\right\}
$$

where the first two terms capture the utility of the utilitarian politician in the first period when he spends $\eta_{u}$ on enforcement, and the state of the world is low (with probability $(1-q)$ ) and high (with probability $q$ ). The remaining two terms represent instead his second period payoff which depends on whether he is re-elected and on the state of the world. Similarly, if the utilitarian plays sincere, his payoff can be written as:

$$
\begin{aligned}
U(\text { sincere }) & =(1-q) u\left[I_{b}(L)\right]+q u\left[I_{b}(H)\right]+ \\
& +\mu\left\{q u\left[I_{p}^{*}(H)\right]+(1-q) u\left[I_{p}^{*}(L)\right]\right\}+(1-\mu)\left\{q u\left[I_{b}^{*}(H)\right]+(1-q) u\left[I_{b}^{*}(L)\right]\right\}
\end{aligned}
$$

Some additional notation is useful to characterize the case where $U$ (under $)>U($ sincere $)$. Let $\Delta_{H}^{1} U($ under $)=u\left[I_{b}^{u}(H)\right]-u\left[I_{b}(H)\right]$ be the first period utility difference from choosing underinvestment rather than the sincere strategy if the state of the world is high. Similarly, let $\Delta_{L}^{1} U($ under $)=u\left[I_{p}(H)\right]-u\left[I_{b}(L)\right]$ be the first period utility difference when the state of the world is low. Finally, let $\Delta^{2} U($ under $)=u\left[I_{b}^{*}(L)\right]-u\left[I_{p}^{*}(L)\right]>0$ be the second period utility

\footnotetext{
${ }^{12}$ If $P[g=p \mid I]>\mu$, then for the median voter it is not optimal to replace the incumbent with a challenger that has a lower probability of being populist, and the opposite is true if $P[g=p \mid I]<\mu$. Finally, if $P[g=p \mid I]=\mu$, dismissing the incumbent is optimal because it induces revelation of types. To see this, first note that when $P[g=p \mid I]=\mu$, dismissing the incumbent is a credible punishment because the median voter is indifferent between keeping him and replacing him with somebody with the same probability of being a populist. Second, since mimicking does not increase re-election chances, the utilitarian politician prefers choosing the social surplus maximizing policy, thus revealing his type.
} 
gain from being in power, when the state of the world is low as compared to being replaced by a populist challenger. Under-investment is preferred if the following holds:

$$
-\left[q \Delta_{H}^{1} U(\text { under })+(1-q) \Delta_{L}^{1} U(\text { under })\right]<(1-q) \mu \Delta^{2} U(\text { under })
$$

The left-hand side of the inequality represents the first period expected utility loss from underinvestment: since the maximization of the one period expected utility requires an enforcement level $\eta\left(I_{b}^{*}\right)>\eta_{u}$, by underinvesting the utilitarian incumbent incurs a utility loss given by $\left[q \Delta_{H}^{1} U(\right.$ under $)+(1-q) \Delta_{L}^{1} U($ under $\left.)\right]<0$. The right hand side represents the expected second period gain from under-investment: if the state of the world is low (which happens with probability $1-q$ ), the utilitarian incumbent will obtain his most preferred level of migration in the second period. Since by playing sincere he could obtain the same gain with the lower probability $(1-q)(1-\mu)$, the expected gain is given by $(1-q) \mu \Delta^{2} U($ under $)$.

As shown by Facchini and Testa (2014), the equilibrium of the game when the incumbent is utilitarian can be characterized as follows: ${ }^{13}$

Proposition 1 Let $\widetilde{\mu}_{u}=-\frac{(1-q) \Delta_{H}^{1} U(\text { under })+q \Delta_{L}^{1} U(\text { under })}{(1-q) \Delta^{2} U(\text { under })}>0$. If $q>\frac{1}{2}$ and $\mu>\widetilde{\mu}_{u}$, there exists a pooling equilibrium with under-investment whereby, if $s=L$, the utilitarian incumbent admits $I_{p}(H)$ migrants and is re-elected, whereas if $s=H, I_{b}^{u}(H)$ migrants are admitted and he is voted out of office. If $q>\frac{1}{2}$ and $\mu<\widetilde{\mu}_{u}$, there exists instead a separating equilibrium such that $I_{b}(L)$ migrants are admitted if $s=L, I_{b}(H)$ are admitted if $s=H$, and the utilitarian incumbent is never re-elected. Finally, if $q \leq \frac{1}{2}$ the utilitarian incumbent plays sincere and is not re-elected.

The first part of the proposition points out that electoral incentives can induce the utilitarian politician to admit on purpose more migrants than the number specified under his official target, by strategically under-investing in enforcement. Moreover, Facchini and Testa (2014) show that reelection concerns raise illegal immigration above the level implied purely by imperfect information on the true supply of foreign workers.

\section{Border vs domestic enforcement}

Having analyzed the main forces inducing a utilitarian politician to adopt a strategic behavior when a single enforcement technology is available, we now extend the model developed by Facchini and Testa (2014) to allow the choice between two different instruments. In particular, we are interested in analyzing whether an enforcement technology that is less cost-effective might be

\footnotetext{
${ }^{13}$ In the case of a populist incumbent, in equilibrium he always chooses the policy preferred by the median voter and is re-elected, because in a separating equilibrium voters can perfectly infer his type, whereas in a pooling equilibrium the number of illegal immigrants generated by the populist never exceeds the threshold required for re-election. See Facchini and Testa (2014) for the proof of these results.
} 
chosen in equilibrium. To fix ideas, the first technology - which we call domestic enforcement can be thought of as coinciding with the type of enforcement activity we have analyzed so far. The second one requires instead more resources to enforce any given migration target under both states of the world. In the policy debate, the control of migration flows carried out at the border is often considered to be less effective than work-site inspections, because effectively patrolling a vast border with its huge number of potential entry points is more costly than effectively checking the working sites where undocumented immigrants are likely to be employed (Hanson 2006). ${ }^{14}$ Hence, we will call our second instrument border enforcement. Naturally, our analysis applies also to any other form of inefficient use of enforcement resources.

Formally, let $\eta^{B}(\hat{I}, I)$ and $\eta^{D}(\hat{I}, I)$ respectively denote the border $(B)$ and domestic $(D)$ enforcement technology, and let

$$
\eta^{B}(\hat{I}, I)>\eta^{D}(\hat{I}, I) \forall \hat{I} \in\{\underline{I}, \bar{I}\}
$$

To simplify the discussion, we make one additional assumption, i.e. that $\eta^{B}(\underline{I}, I)=\eta^{D}(\bar{I}, I)$. In other words, enforcing a given migration target in the low state of the world using the border enforcement technology is as costly as enforcing the same target using the domestic enforcement technology if the state of the world is high. The two instruments are represented in Figure 2. Moving from the left to the right, the first line $\left(\eta^{D}(\underline{I})\right)$ describes the cost of domestic enforcement under the low state of the world. The second line $\left(\eta^{D}(\bar{I})=\eta^{B}(\underline{I})\right)$ captures both the cost of domestic enforcement if the state of the world is high, and the cost of border enforcement if the state is low. The last line $\left(\eta^{B}(\bar{I})\right)$ displays instead the border enforcement cost under the high state of the world.

As in our previous discussion, at the beginning of the game, neither the politician nor the public observe the supply of immigrants $\hat{I}(s)$, but they know its distribution. At the end of the first mandate, voters observe the number of immigrants in the country, but not the amount of resources spent on enforcement nor how the resources have been employed (i.e. on the more or less effective technology). As a consequence, the government can strategically set not only the budget allocated to the enforcement activities, but also decide how the resources are employed. In particular, a utilitarian government can admit the same number of migrants allowed by a populist when the state of the world is high in two alternative ways. First, as before, he can strategically under-invest, spending $\eta_{U}$ and obtaining a migration level $I_{b}^{u}(L)=I_{p}(H)$ and $I_{b}^{u}(H)$ respectively

\footnotetext{
${ }^{14}$ Border enforcement may also be less effective because it only affects the migrant at the time of the illegal border crossing, whereas domestic enforcement implies that the migrant may be apprehended at any point in time after he has entered illegally, and after he has faced destination country-specific sunk costs. Hence, a lower probability of domestic enforcement could generate the same reduction in expected gains from illegal immigration induced by any given probability of being caught at the border. Finally, if domestic enforcement takes the form of worksite inspections, levying fines on employers this will make the policy (fully or partially) self-financing, differently from border enforcement. We would like to thank one of the referees for suggesting these arguments.
} 


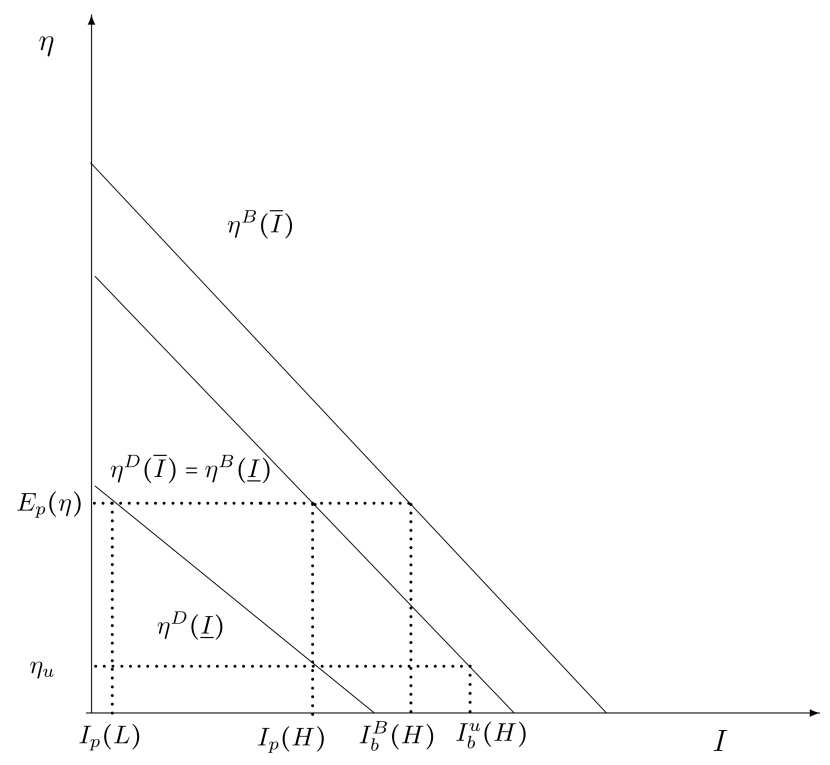

Figure 2: Illegal immigration with domestic and border enforcement

if the state of the world is low and high (see Figure 2). Alternatively, the benevolent politician can spend the amount of resources that would maximize the median voter's welfare $\left(E_{p}(\eta)>\eta_{U}\right)$, but employ them "ineffectively" by adopting border instead of domestic enforcement. Also in this case, if the state of the world is low the number of migrants admitted would be the same chosen by a populist under the high state $\left(I_{p}(H)\right)$, implying that the utilitarian politician might have a chance to be re-elected. On the other hand, if the state is high, the resulting number of migrants would be $I_{b}^{B}(H)$ (see Figure 2).

Given the new strategy space, the updating process of the median voter's beliefs becomes richer. Let $\lambda_{D}$ and $\lambda_{B}$ denote the probability that a utilitarian incumbent generates the outcome $I$ by choosing respectively domestic $(D)$ and border $(B)$ enforcement. As before, $\lambda_{L}$ denotes the probability that a utilitarian incumbent generates an outcome $I$ when the state of the world is low, and $\lambda_{H}$ the probability that he generates the same outcome if the state is high. Then, if voters observe the outcome $I_{p}(H)$, the ex-post probability that the incumbent is a populist can be computed as follows:

$$
P\left[g=p \mid I_{p}(H)\right]=\frac{\mu q}{\mu q+q(1-\mu) \lambda_{H}+\left[\left(\lambda_{D}+\lambda_{B}\right)(1-q)(1-\mu)\right] \lambda_{L}}
$$

where $\mu q$ is the probability that $I_{p}(H)$ is generated by a populist, $q(1-\mu) \lambda_{H}$ is the probability that it is generated by a utilitarian politician mimicking the populist, and $(1-q)(1-\mu) \lambda_{L}$ is the probability that it is generated by a utilitarian politician, either by under-investing in enforcement $\left(\lambda_{D}\right)$ or by choosing the ineffective enforcement technology $\left(\lambda_{B}\right)$.

As in the case with a single enforcement tool, mimicking cannot be optimal since it does not 
generate any positive updating in beliefs. On the other hand, whenever $q>1 / 2$, the adoption of under-investment in domestic enforcement or border enforcement generate the same positive update of beliefs. The next proposition characterizes the optimal choice of a utilitarian politician if $q>1 / 2$ and both domestic and border enforcement are available. Let $u^{j}[I(s)]=\tilde{u}[I(s)]-$ $\eta^{j}[I(s), I]$, with $j=B, D$, where $\tilde{u}[I(s)]=\pi(E)+w(E)-c(I)$ is the component of the utilitarian politician's utility function, that does not depend on the enforcement expenditure. Following the notation we have introduced in section 2 , let $\Delta_{H}^{1} U($ border $)=u\left[I_{b}^{B}(H)\right]-u\left[I_{b}(H)\right]<0$ be the first period utility difference from choosing border enforcement over the sincere policy when the state of the world is high, and $\Delta_{L}^{1} U($ border $)=u\left[I_{p}(H)\right]-u\left[I_{b}^{B}(L)\right]<0$ be the first period utility difference when the state is low. $\Delta^{2} U($ border $)=u\left[I_{b}^{*}(L)\right]-u\left[I_{p}^{*}(L)\right]>0$ denotes instead the second period utility gain from being in power when the state of the world is low. Finally, let us define $\widetilde{\mu}_{B}=-\frac{q \Delta_{H}^{1} U(\text { border })+(1-q) \Delta_{L}^{1} U(\text { border })}{(1-q) \Delta^{2} U(\text { border })}>0$. The following then holds:

Proposition 2 Let $q>1 / 2$ and suppose that $\mu>\widetilde{\mu}_{u}$. Then, if $\tilde{u}\left[I_{b}^{B}(H)\right]-\tilde{u}\left[I_{b}^{u}(H)\right]<0$, the utilitarian politician chooses under-investment in domestic enforcement. If $\tilde{u}\left[I_{b}^{B}(H)\right]-\tilde{u}\left[I_{b}^{u}(H)\right]>$ 0 , then the utilitarian politician chooses border enforcement if and only if $q\left\{\tilde{u}\left[I_{b}^{B}(H)\right]-\tilde{u}\left[I_{b}^{u}(H)\right]\right\} \geq$ $E_{p}(\eta)-\eta_{U}$. On the other hand, if $\mu<\widetilde{\mu}_{u}$, the utilitarian politician chooses border enforcement if $\widetilde{\mu}_{B}<\mu<\widetilde{\mu}_{u}$, whereas he implements the sincere policy if $\mu<\widetilde{\mu}_{u}<\widetilde{\mu}_{B}$ or $\mu<\widetilde{\mu}_{B}<\widetilde{\mu}_{u}$.

Proof. Note that if $\mu>\widetilde{\mu}$, from the proof of Proposition 1 in Facchini and Testa (2014) we know that under-investment with domestic enforcement is preferred to the sincere policy. Hence, border enforcement is chosen over domestic enforcement if the resulting expected payoff is larger. This is true if and only if

$$
q\left\{\tilde{u}\left[I_{b}^{B}(H)\right]-\tilde{u}\left[I_{b}^{u}(H)\right]\right\} \geq E_{p}(\eta)-\eta_{U}
$$

Remember that $E_{p}(\eta)-\eta_{U}>0$. Hence, if $\tilde{u}\left[I_{b}^{B}(H)\right]-\tilde{u}\left[I_{b}^{u}(H)\right]<0$, then inequality 8 is never satisfied, whereas if $\tilde{u}\left[I_{b}^{B}(H)\right]-\tilde{u}\left[I_{b}^{u}(H)\right]>0$, inequality 8 is satisfied if and only if $q\left\{\tilde{u}\left[I_{b}^{B}(H)\right]-\right.$ $\left.\tilde{u}\left[I_{b}^{u}(H)\right]\right\} \geq E_{p}(\eta)-\eta_{U}$. The proof of Proposition 1 in Facchini and Testa (2014) tells us also that if $\mu<\widetilde{\mu}_{u}$, the sincere policy is preferred to domestic enforcement. Hence, border enforcement is chosen over the sincere policy if the resulting payoff is larger, i.e. if and only if

$$
\mu(1-q) \Delta^{2} U(\text { border })>-q \Delta_{H}^{1} U(\text { border })-(1-q) \Delta_{L}^{1} U(\text { border })
$$

and this is true if and only if $\mu>\widetilde{\mu}_{B}$.

The intuition for the result is as follows. In our two-period setting, the incumbent chooses the first period policy by maximizing his expected pay-off that depends on the state of the world (which is not observed either by the policy maker or the public) and on the extent of populist pressures $(\mu)$. The first part of the proposition characterizes the equilibrium policy choice when $\mu>\widetilde{\mu}_{u}$. In order to understand how the expected payoff of the utilitarian politician depends on the state of 
the world, note that when the state of the world is low, domestic enforcement is more desirable because it delivers the same number of migrants as border enforcement using less resources. On the other hand, if the state of the world is high, under-investment and border enforcement do not deliver the same number of migrants, because the latter, while employing more resources, generates less migrants, as shown in Figure 2. The desirability of one instrument over the other crucially depends on the preferences of the utilitarian politician on the optimal number of migrants to be admitted, $I_{b}^{*}$. In particular, if $I_{b}^{*}<I_{b}^{B}(H)$, then border enforcement is less distortive because the expected number of migrants it generates is closer to the utilitarian ideal point $I_{b}^{*}$ as compared to domestic enforcement with under-investment. On the other hand, if $I_{b}^{*}>I_{b}^{B}(H)$, then border can be more or less distortive than domestic enforcement, depending on whether it generates a number of migrants that is further away from or closer to the utilitarian's ideal point as compared to the other technology. Note that, if border is more distortive (e.g. $\left.\tilde{u}\left[I_{b}^{B}(H)\right]-\tilde{u}\left[I_{b}^{u}(H)\right]<0\right)$, then it is clearly dominated by domestic under-investment as the latter is also less costly. On the other hand, if border is less distortive (e.g $\tilde{u}\left[I_{b}^{B}(H)\right]-\tilde{u}\left[I_{b}^{u}(H)\right]>0$ ), then it dominates domestic under-investment provided that the utility gain in terms of number of migrants outweighs the larger cost of enforcement (e.g. $\left.q\left\{\tilde{u}\left[I_{b}^{B}(H)\right]-\tilde{u}\left[I_{b}^{u}(H)\right]\right\} \geq E_{p}(\eta)-\eta_{U}\right)$. The second part of the proposition (i.e. when $\mu<\widetilde{\mu}_{u}$ ) shows that, even if the sincere policy is preferred to domestic enforcement, border enforcement might still be chosen in equilibrium. In other words, allowing for an additional instrument besides under-investment enables the utilitarian politician to sustain a pooling equilibrium in which he can generate "excessive" illegal immigration that could have not been achieved if only under-investment was available.

In our analysis so far, voters are uninformed both concerning the amount of resources spent and on the effectiveness of the enforcement technology. After September 11, 2001 migration policy in the US has come under increased scrutiny, and much attention has been focused on the activities of the newly established Department of Homeland Security. While policy-makers still retain a substantial information advantage because the publicly available data on the enforcement budget are typically not very detailed, the public might have become more informed on the total amount of resources spent on enforcement as compared to the effectiveness of different enforcement technologies. How will our results be affected by this change in the information setting? To characterize this asymmetry in the simplest way, let us assume that the public can observe only the amount of resources spent on enforcement. When the enforcement budget is known, the underinvestment strategy allows the public to perfectly infer the politician's type. As a consequence, an equilibrium with under-investment in domestic enforcement cannot arise. On the other hand, inefficiently high illegal immigration can still occur as a result of an ineffective use of the resources spent on enforcement. In particular, we can show that the following holds:

Corollary 1 Suppose that the median voter observes the amount of resources spent on enforcement. Then the utilitarian politician chooses border enforcement if $\mu>\widetilde{\mu}_{B}$, whereas he chooses 
the sincere policy if $\mu<\widetilde{\mu}_{B}$.

Proof. Since the sincere strategy is always preferred to domestic enforcement, then border enforcement is chosen if and only if it delivers a higher payoff than the sincere strategy and this is true if and only if if $\mu>\widetilde{\mu}_{B}$.

Note that, when more information on enforcement spending becomes available to the public, domestic enforcement with under-investment can no longer be used by the utilitarian politician to "pool" with the populist. As a result, the former will resort more often to the adoption of the sincere policy to admit the constrained socially optimal number of migrants in the first period, losing elections. He will then be replaced by a challenger, which is populist with probability $\mu$ and utilitarian with probability $1-\mu$. Therefore, in a sincere equilibrium the utilitarian incumbent does not distort his first period policy choice, but is less likely to win election and choose the social surplus maximizing policy in the second period. To understand how information revelation affects the welfare of the average voter, consider a benchmark case where the public is perfectly informed about enforcement. In this scenario, since the utilitarian politician always plays sincere, the average voter obtains his most preferred policy in the first period, whereas in the second period his most preferred policy is chosen with probability $1-\mu$ and the policy preferred by the median voter is implemented with probability $\mu$. On the other hand, when the public cannot observe enforcement, the utilitarian politician may decide to distort his first period policy choice in order to increase his re-election chances. In this case the average voter scores worse in terms of 'discipline', as the first period policy is distorted, but fairs better in terms of 'selection', since the utilitarian incumbent is more likely to be re-elected. Since the utilitarian policy-maker acts by maximizing expected average welfare, he only distorts the first period policy if the 'selection' gain is larger than the first period distortion. As a result, although distortive, the policy chosen in the asymmetric information scenario is in fact welfare enhancing because it allows the utilitarian politician to be re-elected with higher probability bringing the overall number of migrants closer to the social optimum. If instead of the average voter we consider the well-being of the majority, the results are reversed, because asymmetric information makes the discipline and selection problems harder for the median voter.

\section{Conclusion}

In this paper we have developed a model to study how governments choose migration policy enforcement when they can use alternative tools characterized by different degrees of cost effectiveness. We have shown that electoral concerns may induce a policy maker to choose sub-optimal enforcement, which leads to "excessively high" illegal immigration. We have considered two sources of policy inefficiency. On the one hand, the government might strategically under-fund migration control operations; on the other, it might respond to public pressure for adequate funding, but 
strategically use the resources in an ineffective way. We have shown that, as long as the policy maker has an information advantage over the public concerning the way it controls migration flows, it might find it optimal to announce a target pleasing a majority of the electorate, but then strategically relax its enforcement, by either under-investing or using resources ineffectively. Our results provide a rationale not only for the disproportionate amount of resources devoted to ineffective enforcement tools - such as border control - at the expense of arguably more effective ones - such domestic work-site inspections - but also highlights the factors that induce an elected government to choose one policy tool over the other. The size of the supply of migrants is key to determine the choice of instrument. In particular, when the supply of foreign workers is large, border enforcement might be preferred because, although more costly, it could bring the number of migrants closer to the utilitarian optimum, thus reducing the policy distortion driven by strategic motives. These results have important policy implications. First, they indicate that electoral considerations are responsible for wasteful spending on enforcement because, in an attempt to bring migration closer to his most preferred outcome while avoiding electoral punishment, a utilitarian politician spends an excessive amount of resources on a ineffective policy tool. Second, since border control may be desirable only when the supply of potential migrants is large, countries that are more exposed to

large migratory pressures, might also be more likely to resort to inefficient enforcement tools. As a result, we cannot escape the somewhat troublesome conclusion that enforcement is carried out in the least effective way when migration is a most pressing problem.

\section{References}

Alesina, A. and D. Rodrik (1994). Distributive politics and economic growth. Quarterly Journal of Economics 109, 465-490.

Benhabib, J. (1996). On the political economy of immigration. European Economic Review 40, $1737-1743$.

Besley, T. and M. Smart (2007). Fiscal restraint and voter welfare. Journal of Public Economics 91, 755-773.

Bond, E. W. and T. J. Chen (1987). The welfare effects of illegal immigration. Journal of Development Economics 23, 315-328.

Chau, N. H. (2001). Strategic amnesty and credible immigration reform. Journal of Labor Economics 19, 604-633.

Chiswick, B. R. and T. Hatton (2003). International migration and the integration of labor markets. In M. Bordo, A. Taylor, and J. Williamson (Eds.), Globalization in Historical Perspective, Chapter 3, pp. 65-119. Chicago: University of Chicago Press. 
Coate, S. and S. Morris (1995). On the form of transfers to special interests. Journal of Political Economy 103, 1210-1235.

Cornelius, W. A., T. Takeyushi, P. L. Martin, and J. F. Hollifield (2004). Controlling Immigration: A Global Perspective. Stanford: Stanford University Press.

Dutt, P. and D. Mitra (2002). Endogenous trade policy through majority voting: An empirical investigation. Journal of International Economics 58, 107-134.

Ethier, W. J. (1986). Illegal immigration: The host country problem. American Economic Review 76, 56-71.

Facchini, G., A. M. Mayda, and P. Mishra (2011). Do interest group affect us immigration policy? Journal of International Economics 85, 114-128.

Facchini, G. and C. Testa (2011, revised 2014). The rhetoric of closed borders: quotas, lax enforcement and illegal immigration. CEPR DP 8245.

Facchini, G. and G. Willmann (2005). The political economy of international factor mobility. Journal of International Economics 67, 201-219.

Fasani, F. (2009). Deporting undocumented immigrants: The role of labor demand shocks. mimeo, University College London.

Hanson, G. H. (2006). Illegal migration from Mexico to the United States. Journal of Economic Literature 44, 869-924.

Hanson, G. H. and A. Spilimbergo (2001). Political economy, sectoral shocks, and border enforcement. Canadian Journal of Economics 34, 612-638.

House of Commons, Home Affairs Committee (2011). The work of the UK Border Agency (November 2010-March 2011). London: The Stationery Office Limited.

Massey, D. D. S., J. Durand, and N. J. Malone (2002). Beyond Smoke and Mirrors: Mexican Immigration in an Era of Economic Integration. New York: The Russell Sage Foundation.

Ortega, F. (2005). Immigration policy and skill upgrading. Journal of Public Economics 89, 1841-1863.

Triandafyllidou, A. (2009). Clandestino project final report. mimeo.

United States General Accounting Office (2005). Preliminary observations on employment verification and worksite enforcement efforts. Report 05-822T, GAO. 
Table1. Border patrol and worksite inspections

\begin{tabular}{|c|c|c|c|c|c|c|}
\hline & 1999 & 2000 & 2001 & 2002 & 2003 & Average \\
\hline INS/ICE apprehensions & 135406 & 137940 & 120669 & 107262 & 115060 & 123267 \\
\hline Border Patrol apprehensions & 1578594 & 1677060 & 1266331 & 954738 & 930940 & 1281533 \\
\hline Worksite inspection hours & 480000 & 352000 & 234000 & 264000 & 180000 & 302000 \\
\hline Line-watch border patrol hours & 8740258 & 8999552 & 9802081 & 9183667 & 9457060 & 9236524 \\
\hline Worksite inspection hours per apprehension & 3.5 & 2.6 & 1.9 & 2.5 & 1.6 & 2.4 \\
\hline Line-watch border patrol hours per apprehension & 5.5 & 5.4 & 7.7 & 9.6 & 10.2 & 7.7 \\
\hline
\end{tabular}

Source: Hanson (2006) and GAO (2005) 